\title{
Maxillofacial Radiology 179
}

SADJ April 2020, Vol. 75 No. 3 p160

CJ Nortjé

Below are images of three patients presenting at the department due to the effects of multimodality therapies of childhood cancer on the developing dentition. What are the important developing abnormalities discernible?
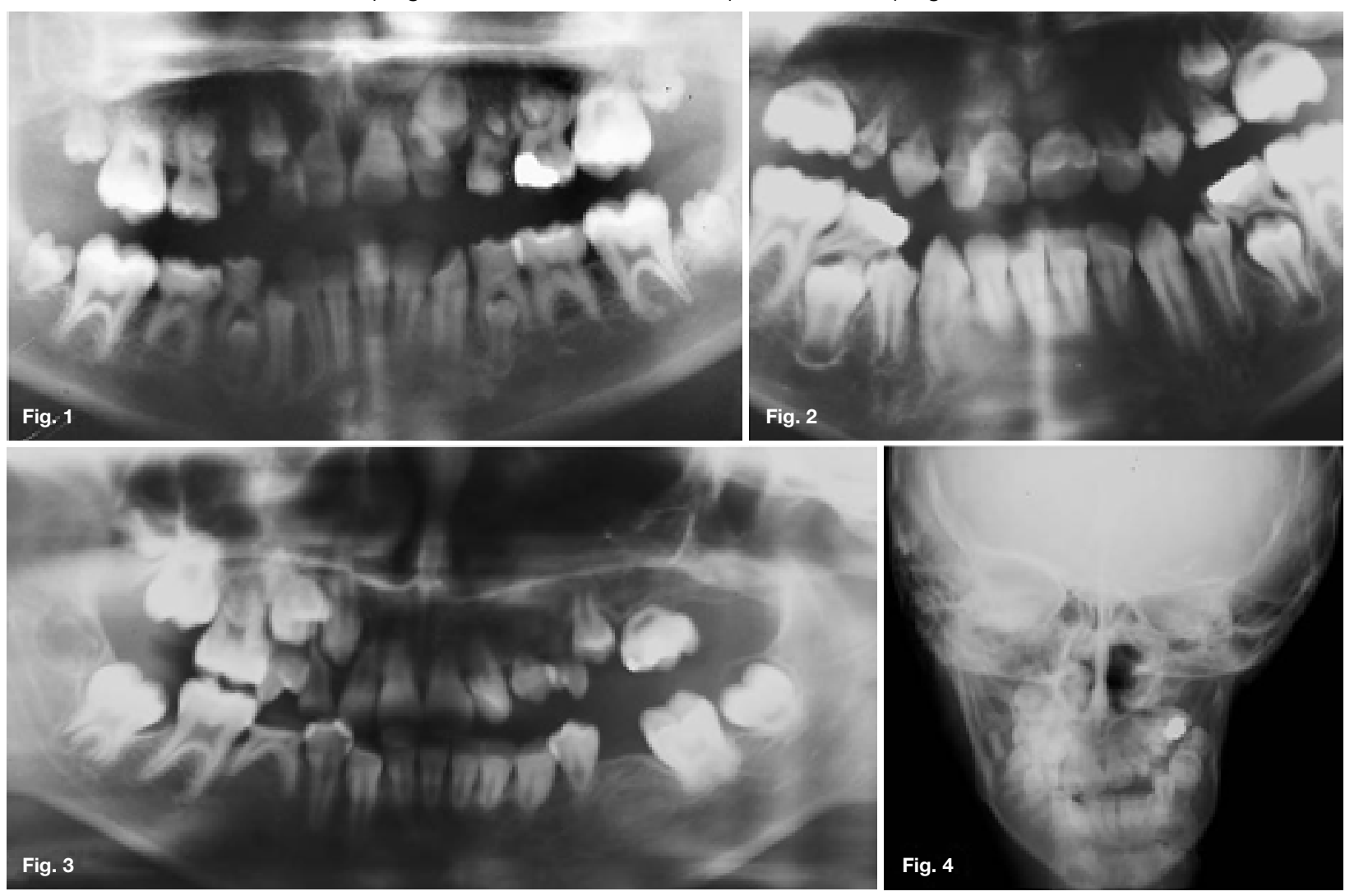

INTERPRETATION

Figure 1 is a radiograph of a ten year old female presenting with a history of radiation treatment for a $T$ cell lymphoma. It is a type of cancer that forms in $T$ cells (a type of immune system cell). T-cell lymphomas may be either indolent (slow-growing) or aggressive (fast-growing). Most T-cell lymphomas are non-Hodgkin lymphomas. There are many different types of T-cell non-Hodgkin lymphomas. Reported abnormalities include hypodontia, microdontia, enamel hypoplasia, root stunting, taurodontia, over-retention of primary teeth, an increased caries index and decreased temporomandibular joint mobility. Existing reports have found that children may be at greater risks for odontogenic developmental abnormalities if treated with chemotherapy when younger than 5 years because of proliferation of dental stem cells during this period. Figure 2 is a pantomograh of a ten year old male who had been treated at the age of 2 years for bilateral retinoblastoma. At the time he received a total of 40 Gray at $250 \mathrm{kVp}$ over a 4-week period directed at both orbits. The radiograph shows extensive resorption of the roots of all the maxillary teeth. Figures $3 \& 4$ are images

Christoffel J Nortjé: $B C h D, P h D, A B O M R, D S c$. Faculty of Dentistry, University of the Western Cape.

ORCID Number: 0000-0002-9717-5514

Email: cnortje@uwc.ac.za of a ten year old female who had been radiated at the age of 2 years for a retinoblastoma of the left eye. The exact dosage could not be determed. The clinical and radiographic examination revealed that the permanent teeth in the left maxilla and mandible had been affected. Radiographic examination of the alveolar bone revealed to be more radiolucent on the left side than the right side. Retinoblastoma presents as a rapidly developing carcinoma developing from immature cells of the retina, which is reported to be the most common malignant tumour affecting the eyes during childhood. Sixty five percent of the affected cases present with unilateral retinoblastoma. Treatment includes surgical enucleation of the affected eye, external beam radiotherapy, brachytherapy, cryotherapy and chemotherapy. The side-effects of various cancer treatment modalities especially radiotherapy present as a plethora of skeletal and dental anomalies.

\section{Reference}

1. Khan M, Maheshwari S, Khan MT, Verma SK: Long term dento-facial effects of radiotherapy in a treated patient with retinoblastoma. Journal of Oral Biology and Craniofacial Research. 2014; 4(3): 214-217.

2. Harris AMP, Nortje CJ, Luchessi AMV: Some effects of radiation therapy during early childhood on facial growth and tooth development. SADJ. 1986; 41: 681-6. 